\title{
Racismo à brasileira e possíveis contribuições do pensamento de Paulo Freire para uma educação antirracista
}

\author{
Crislei de Oliveira Custódio*
}

\section{Resumo}

Este artigo tem como objetivo debater alguns elementos presentes na obra de Paulo Freire com intuito de pensar, a partir daí, possíveis contribuições do pensamento freiriano para as bases de uma educação antirracista. Para isso, parte-se da conceituação das noções de raça, racismo, preconceito e discriminação racial e da abordagem acerca de algumas especificidades da questão racial no Brasil para contextualizar o tema do racismo. Em seguida, retoma-se a ideia de dominação enunciada na contradição opressor-oprimido e a discussão proposta por Paulo Freire acerca da necessidade de descolonização do currículo no processo de reconstrução de Guiné-Bissau e, com base no pensamento da pensadora estadunidense bell hooks ${ }^{1}$, são analisados alguns fundamentos para uma concepção antirracista de educação.

Palavras-chave: racismo, educação antirracista, descolonização do currículo, Paulo Freire.

\section{Brazilian racism and possible contributions of Paulo Freire's thought to an anti-racist education}

\section{Abstract}

This article aims to debate some elements present in Paulo Freire's work to think, from there, possible contributions of Freirian thought to the foundations of an anti-racist education. For that, it starts from the con-

Doutora em Educação pela Universidade de São Paulo e Professora Titular do Programa de Pós-Graduação em Educação da Universidade Ibirapuera. E-mail: crislei.paula@usp.br

1 bell hooks é o pseudônimo utilizado pela escritora estadunidense Gloria Jean Watkins. O nome é referida no diminutivo por exigência da própria pensadora. 
ceptualization of the notions of race, racism, prejudice and racial discrimination and from the approach about some specificities of the racial issue in Brazil to contextualize the theme of racism. Then, the idea of domination, expressed in the oppressor-oppressed contradiction, and the discussion proposed by Paulo Freire about the need to decolonize the curriculum in the process of reconstructing Guinea-Bissau and, based on the thinking of the American thinker bell hooks, are resumed some fundamentals for an anti-racist conception of education are analyzed.

Keywords: racism, anti-racist education, decolonizing the curriculum, Paulo Freire.

\section{El racismo brasileño y las posibles contribuciones del pensamiento de Paulo Freire a una educación anti-racista}

\section{Resumen}

Este artículo tiene como objetivo debatir algunos elementos presentes en el trabajo de Paulo Freire para pensar, a partir de ahí, las posibles contribuciones del pensamiento freiriano a los fundamentos de una educación antirracista. Para eso, parte de la conceptualización de las nociones de raza, racismo, prejuicio y discriminación racial y del enfoque sobre algunas especificidades de la cuestión racial en Brasil para contextualizar el tema del racismo. Luego, se reanuda la idea de dominación, expresada en la contradicción opresivo-oprimida, y la discusión propuesta por Paulo Freire sobre la necesidad de descolonizar el plan de estudios en el proceso de reconstrucción de Guinea-Bissau y, basándose en el pensamiento de la pensadora estadounidense bell hooks, se analizan algunos fundamentos para una concepción anti-racista de la educación.

Palabras claves: racismo, educación anti-racista, descolonización del currículo, Paulo Freire.

\section{Introdução}

Escrito por Paulo Freire durante o seu período de exílio no Chile e publicado em 1968, o livro Pedagogia do Oprimido tornou-se uma referência mundial sendo, de acordo com dados pesquisados por Elliott Green, professor da Escola de Economia e Ciência Política de Londres, "a terceira publicação mais citada em trabalhos na área de humanas" (SANTANA; SOUZA, 2019, p. 4). O contexto 
histórico em que a obra foi redigida e publicada é marcado pelo recrudescimento do regime militar no Brasil com o decreto do Ato Institucional n. 5, de dezembro de 1968, e pelo avanço das ditaduras militares nos países da América do Sul². À mesma época, a Guerra do Vietnã já passava de uma década desde o seu início e as tensões em torno da polarização provocada pela Guerra Fria aumentavam, eclodiam também manifestações estudantis em universidades de diferentes países ocidentais das quais o movimento de Maio de 68, na França, tornou-se o principal símbolo; e, na África, o processo de descolonização vivia o seu auge desde de 1960 com a queda dos principais impérios coloniais europeus no continente e independência de muitos países ${ }^{3}$.

2 Desde a década de 1950, como efeito da Guerra Fria e, na maioria dos casos, da suposta ameaça comunista, iniciou-se um processo político na América Latina que culminou em uma sequência de golpes militares que instauraram ditaduras nos países do continente. Mais especificamente na América do Sul, esse processo teve início com o Paraguai, em 1954, quando o presidente Federico Chávez foi deposto por tropas militares sob o comando do general Alfredo Stroessner. Em 1962, foi a vez do presidente argentino Arturo Frondizi sofrer um golpe (Juan Domingo Perón já havia sido destituído em 1955 por forças militares, as quais chamaram nova eleição em 1958, nas quais Frondizi foi eleito); sendo seguido pelo presidente João Goulart no Brasil, em 1964; por Victor Paz Estenssoro, também em 1964, na Bolívia; Fernando Belaúnde Terry em 1968 no Peru; e, Salvador Allende em 1973 no Chile.

Cf. GESTEIRA, L. A. M. G. A Guerra Fria e as Ditaduras Militares na América do Sul. Scientia Plena, vol. 10, n. 12, 2014. Disponível em: https://www. scientiaplena.org.br/sp/article/view/2062/1097\#

3 Segundo Visentini (2008, pp. 123-4), “em 1960, o "ano africano", a maioria dos países do continente tornou-se independente da França e da Grã-Bretanha, dentro da linha "pacífica", gradual e controlada: Camarões, Congo-Brazzaville, Gabão, Chade, República Centro-africana, Togo, Costa do Marfim, Daomé (atual Benin), Alto Volta (atual Burkina Fasso), Níger, Nigéria, Senegal, Mali, Madagascar, Somália, Mauritânia e Congo-Leopoldville (atual Zaire). Entre 1961 e 1966 foi a vez de Serra Leoa, Tanzânia, Uganda, Ruanda, Burundi, Quênia, Gâmbia, Botswana e Lesoto. Todos os novos Estados localizavam-se na zona tropical africana e, neles, era limitado o número de colonos europeus, o que facilitou a transferência do controle formal dos diversos países à burguesia e classe média negra”. 
Partindo da contradição opressor-oprimido, a qual se referencia na dialética hegeliana do senhor e do escravo, Paulo Freire disserta sobre a necessidade "de uma pedagogia dialógica emancipatória do oprimido, em oposição à pedagogia da classe dominante, que contribua para a sua libertação e sua transformação em sujeito cognoscente e autor da sua própria história através da práxis" (CABRAL, 2005, p. 200). Assim, por meio da superação da contradição opressor-oprimido, a qual imputa ao oprimido uma consciência dominada que estabelece nele a dualidade de ser ele próprio e, ao mesmo tempo, hospedeiro do opressor, os sujeitos podem libertar a si e àquele que os oprime, alcançando, por meio da educação como prática da liberdade, a conscientização e a sua palavra. De acordo com Gadotti (2012, p. 459), "se é pela palavra que o ser humano revela sua humanidade, é no diálogo que ele se encontra com o outro, completando a sua humanidade", assim, na perspectiva freiriana, "o diálogo dos oprimidos, orientados por uma consciência crítica da realidade, aponta para a superação do conflito desses com seus opressores".

Em sua análise da relação opressor-oprimido e sob a influência do pensamento marxiano e das produções de autores marxistas como Gramsci e Lukács (SCOCUGLIA, 1999), Freire concebe a dinâmica da opressão, principalmente, a partir da perspectiva de classe, não fazendo menção explícita às questões relacionadas à ideia de raça e ao racismo. Segundo Scocuglia (1999, p. 34) em seu mapeamento das influências teóricas de Paulo Freire:

Primeiramente, percebeu-se uma incorporação aberta de certos parâmetros políticos e ideológicos propostos pelos clássicos socialistas, especialmente Marx - destacando-se várias referências a escritos como $A$ sagrada família, A ideologia alemã e Teses sobre Feuerbach, relativos à denominada "superestrutura". Na Pedagogia do oprimido já aparecem "classes" no contexto da opressão social, embora não constituam, ainda, categorias centrais da construção do seu discurso. Em Ação cultural para a liberdade e outros escritos a educação começa a ser efetivamente pensada no interior do conflito de classes, como ato de conhecimento "de classe" em busca da mobilização/ organização dos oprimidos, enquanto "ação cultural" que constrói a "consciência de classe" - e, esta só seria conquistada no conflito, na luta pela mudança estrutural da sociedade. 
Ora, mas se assim o é, em que medida é possível pensar possíveis contribuições da obra freiriana para a concepção de uma educação antirracista? De que maneira a educação enquanto prática da liberdade pode contribuir para o enfrentamento da opressão relacionada à questão racial? Embora esse não tenha sido um tema explorado por Freire, entende-se que sua aproximação de pensadores engajados na luta anticolonial e com as teorias pós-coloniais, como Franz Fanon, Amílcar Cabral e Albert Memmi oferece chaves de compreensão da noção de consciência colonizada e de educação comprometida com a emancipação dos sujeitos. Em vista disso, neste artigo abordar-se-ão as distinções entre racismo, discriminação e preconceito, passando-se para uma breve exposição sobre as especificidades do racismo à brasileira e, por fim, tratar-se-á da importância da descolonização do currículo como parte das ações voltadas para a promoção de uma educação antirracista.

\section{Racismo, Preconceito e discriminação: uma distinção necessária}

Entender a problemática da questão racial e as respectivas distinções entre racismo, preconceito e discriminação requer, inicialmente, um recuo analítico que consiste na compreensão do conceito de raça. Como se sabe atualmente, sobretudo após a conclusão dos estudos do Projeto Genoma Humano, a espécie humana não pode ser classificada em raças, isso significa que "a raça não é uma realidade biológica, [...] ou seja, biológica e cientificamente, as raças não existem" (MUNANGA, 2004, n. p.). Essa afirmação, em geral, costuma levar a um questionamento corriqueiro: se a espécie humana, do ponto de vista da Biologia, não pode ser subdivida em raças, por que essa categoria é ainda mobilizada no campo das ciências humanas? Para respondê-la, parte-se da ideia de que raça é um conceito socioantropológico que, intrinsecamente atrelado a circunstâncias históricas e contingenciais, constitui uma realidade social. De acordo com Almeida (2018, p. 19), "por trás da raça sempre há contingência, conflito, poder e decisão, de tal sorte que se 
trata de um conceito relacional e histórico. Assim, a história da raça ou das raças é a história da constituição política e econômica das sociedades contemporâneas".

A classificação da diversidade humana através da ideia de raça é um fenômeno moderno que, como destacam Munanga (2004) e Almeida (2018), tem início no século XVI, relacionando-se diretamente com a expansão marítima europeia, o mercantilismo e o colonialismo. Foram "a expansão econômica mercantilista e a descoberta do novo mundo [que] forjaram a base material a partir da qual a cultura renascentista iria refletir sobre a unidade e a multiplicidade da existência bumana" (ALMEIDA, 2018, pp. 19-20), uma vez que o encontro com povos e culturas distintas da civilização europeia estabeleceu, na relação de dominação desses povos (africanos e ameríndios), a necessidade de ressignificação da ideia de humanidade a partir da noção "nós" e "outros", a qual, no curso do processo histórico, culminou, mais adiante, na oposição entre civilizados e selvagens. Depreende-se daí que, com as grandes descobertas, a unidade e a multiplicidade da existência humana se tornam uma questão filosófica e teológica que, com a ascensão do Iluminismo no século XVIII, ganham novos contornos por meio da emergência da ideia de raça como conceito e categoria de pensamento.

Segundo Almeida (2018, p. 20), "a novidade do Iluminismo é o conhecimento que se funda na observação do homem em suas múltiplas facetas e diferenças 'enquanto ser vivo (biologia), que trabalha (economia), pensa (psicologia) e fala (linguística)", portanto, "do ponto de vista intelectual, o Iluminismo constituiu as ferramentas que tornariam possível a comparação e, posteriormente, a classificação, dos mais diferentes grupos humanos a partir de características físicas e culturais". Nesse sentido, é no século das luzes que os filósofos passam a contestar o monopólio do conhecimento por parte da Igreja, o que faz com que eles recoloquem "em debate a questão de saber quem eram esses outros, recém descobertos" lançando mão "do conceito de raça já existente nas ciências naturais para nomear esses outros que se integram à antiga humanidade como raças di- 
ferentes, abrindo o caminho ao nascimento de uma nova disciplina chamada História Natural da Humanidade" (MUNANGA, 2004, n.p.). Como critérios objetivos dessa classificação, a cor da pele torna-se, inicialmente, característica fundamental de designação do pertencimento a grupos raciais, sendo-lhe acrescidos, posteriormente, "critérios morfológicos como a forma do nariz, dos lábios, do queixo, do formato do crânio, o angulo facial, etc." (MUNANGA, 2004, n. p.). Essa classificação da diversidade humana operada a partir de critérios objetivos que, tomados como diferenças em essência e na forma de categorias de caráter biologizante, passa a constituir "uma das tecnologias do colonialismo europeu para destruição de povos nas Américas, da África, da Ásia e da Oceania" (ALMEIDA, 2018, p. 22).

O desenvolvimento das ciências, da medicina, da psiquiatria, da criminologia, dentre outras, chancelaram a transformação do estudo sobre as diferenças humanas, tornando o homem de objeto filosófico a objeto científico. Assim, características físicas e biológicas, bem como condições climáticas e ambientais passam a ser associadas a fatores morais, intelectuais e psicológicos. $\mathrm{Na}$ atualização da dicotomia civilizado e selvagem nas teorias raciais do século XIX, determinados traços físicos (em especial, a cor da pele) e elementos culturais passam a ser entendidos em uma ordem hierárquica que estabelece uma relação de superioridade e inferioridade entre os grupos raciais. Cabe destacar que o discurso da inferioridade racial dos povos colonizados, justificado pelas bases científicas do século XIX, constituiu argumento ideológico do neocolonialismo (ALMEIDA, 2018, p. 23). Ao mencionar os naturalistas do XVIII e XIX, Munanga (2004, n.p.) afirma que eles erigiram:

[...] uma relação intrínseca entre o biológico (cor da pele, traços morfológicos) e as qualidades psicológicas, morais, intelectuais e culturais. Assim, os indivíduos da raça "branca", foram decretados coletivamente superiores aos da raça "negra" e "amarela”, em função de suas características físicas hereditárias, tais como a cor clara da pele, o formato do crânio (dolicocefalia), a forma dos lábios, do nariz, do queixo, etc. que segundo 
pensavam, os tornam mais bonitos, mais inteligentes, mais honestos, mais inventivos, etc. e consequentemente mais aptos para dirigir e dominar as outras raças, principalmente a negra mais escura de todas e consequentemente considerada como a mais estúpida, mais emocional, menos honesta, menos inteligente e portanto a mais sujeita à escravidão e a todas as formas de dominação.

Diante disso, pode-se concluir que a conformação histórica da ideia de raça postula dois registros básicos que engendram a sua operação: "1. como característica biológica, em que a identidade racial será atribuída por algum traço físico, como a cor da pele; 2 . como característica étnico-racial, em que a identidade será associada à origem geográfica, à religião, à língua ou outros costumes, 'a uma certa forma de existir"' (ALMEIDA, 2018, p. 24). Assim, embora a raça não seja uma realidade biológica, como já afirmado, ela é uma realidade social e elemento político que tem sustentado, ao longo da história, relações de dominação e opressão. O conceito de raça, portanto, é a pedra angular das noções de racismo e de discriminação e preconceito racial.

De acordo com Almeida (2018, p. 25):

[...] o racismo é uma forma sistemática de discriminação que tem a raça como fundamento e que se manifesta por meio de práticas conscientes ou inconscientes que culminam em desvantagens ou privilégios para indivíduos, a depender do grupo racial ao qual pertençam.

Nessa perspectiva, o racismo é uma ideologia que, ao cunhar a categoria raça, classifica e hierarquiza os grupos humanos com base em características fenotípicas e culturais e, de forma sistêmica, opera mecanismos de segregação que produzem e reproduzem privilégios e desvantagens associados aos grupos racializados. A repetição histórica da ordem discriminatória operada pelo racismo transforma as diferenças definidoras dos grupos raciais em desigualdades. Para Cavalleiro (2010, p. 22), “o racismo atribui inferioridade a uma raça e está baseado em relações de poder, legitimadas pela cultura dominante", de modo que, no Brasil, ele "pode ser identificado quando se realiza uma leitura comparativa, quantitativa 
e qualitativa, das desigualdades sociais e das suas consequências na vida das populações negra e branca”.

Como se pode inferir, preconceito e discriminação são conceitos que se relacionam com a ideia de racismo, porém, constituem significados distintos entre si. O preconceito, como a própria palavra enuncia, diz respeito a concepções e juízos prévios, geralmente negativos, balizados por estereótipos acerca dos indivíduos pertencentes a determinados grupos raciais. Considerar pessoas negras violentas ou com inclinação "natural" para a criminalidade, indígenas preguiçosos ou judeus mesquinhos e gananciosos são exemplos de preconceitos. Os preconceitos costumam se manter a despeito dos fatos, pois, como julgamentos prévios que são, eles prescindem da experiência concreta. Nesse sentido, a vinculação entre cor da pele e confiabilidade e honestidade, no caso das pessoas brancas, e entre cor da pele e desconfiança e criminalidade, no caso das pessoas negras, tende a se manter como categorias de julgamento racial ainda que os dados estatísticos afirmem o contrário ou que a própria experiência do convívio com pessoas negras e brancas não valide esse preconceito. Logo, o preconceito é "um modo efetivo e categórico de funcionamento mental que inclui pré-julgamento rígido e julgamento errado dos grupos humanos" (PETTIGREW apud CAVALLEIRO, 2010, p. 23). No Brasil, o preconceito racial assume como essência a negação parcial ou total da humanidade de pessoas negras, uma vez que constitui empecilho para que essas pessoas possam ser reconhecidas individualmente por aquilo que são e não por um conjunto de significados estereotipados e negativos que as definem sempre como coletividade.

A discriminação racial, por seu turno, "é a atribuição de tratamento diferenciado a membros de grupos racialmente identificados. Portanto, a discriminação tem como requisito fundamental o poder, ou seja, a possibilidade efetiva do uso da força" (ALMEIDA, 2018 , p. 25), a qual permite atribuir vantagens ou desvantagens em virtude da raça. Ela "se evidencia quando, em condições sociais dadas, de suposta igualdade entre brancos e negros, se identifica 
um favorecimento para um determinado grupo nos aspectos social, educacional e profissional" (CAVALLEIRO, 2010, p. 26). Assim sendo, o preconceito pode resultar em práticas discriminatórias ou não enquanto a discriminação, em sua forma sistêmica, é a manifestação aparente e ativa do racismo.

Dessa maneira, o racismo - esse processo histórico e social que não se encerra em um ato discriminatório ou em um conjunto de atos, mas que opera a manutenção de um sistema de distribuição de vantagens e desvantagens, de subalternização e favorecimento entre grupos raciais - pode ser concebido, segundo Sílvio Almeida (2018), na dimensão individual, institucional e estrutural. Tomado como manifestação individual, o racismo, nessa acepção, se materializa por meio de comportamentos preconceituosos e atitudes discriminatórias de indivíduos ou grupos isolados, os quais, em uma perspectiva analítica de caráter individualista, tende a ser compreendido como desvio moral ou irracionalidade. A concepção institucional entende o racismo como resultado do funcionamento das instituições e das relações de poder que se dão em seu bojo, sendo que os conflitos raciais são tidos como parte dessas instituições. "Assim, a desigualdade racial é uma característica da sociedade não apenas por causa da ação isolada de grupos ou indivíduos racistas, mas fundamentalmente porque as instituições são hegemonizadas por determinados grupos raciais que", por meio da dominação, "utilizam mecanismos institucionais para impor seus interesses políticos e econômicos" (ALMEIDA, 2018, p. 30). Por fim, na abordagem estrutural, o racismo não se caracteriza apenas pelo poder como elemento fulcral da relação racial e pelo domínio por meio da mobilização de parâmetros e padrões discriminatórios que estabelecem a hegemonia de um grupo racial. Nessa concepção, "o racismo é uma decorrência da própria estrutura social, ou seja, do modo 'normal' com que se constituem as relações políticas, econômicas, jurídicas e até familiares, não sendo uma patologia social e nem um desarranjo institucional" (ALMEIDA, 2018, p. 38). Destarte, "comportamentos individuais e processos institucionais são derivados de uma sociedade cujo racismo é regra e não exceção" (ALMEIDA, 2018, p. 38). 


\section{Notas sobre o racismo à brasileira}

Embora este artigo não pretenda se aprofundar nas formas de operação do racismo no Brasil, faz-se necessário debater algumas especificidades brasileiras que marcam esse processo de dominação e de distribuição de vantagens e desvantagens para indivíduos pertencentes a determinados grupos raciais que, segundo a concepção estrutural do racismo, constitui a estrutura e ordena a sociedade brasileira.

De acordo com Munanga (2017, p. 33):

O racismo é um fenômeno presente em diversas sociedades contemporâneas, latente na cultura, nas instituições e no cotidiano das relações entre seres humanos. No entanto, há pessoas que não o enxergam ou preferem não vê-lo. Ele tem um percurso e várias histórias, que devem ser interpretadas de acordo com épocas, modelos culturais e estruturas de poder das sociedades que o praticam. Apesar de obedecer a uma mesma lógica de hierarquização dos "outros", o racismo passa, no decorrer dos anos, por uma complexidade de mutações em suas figuras sociais, culturais e discursivas. Em sua evolução, a ciência biológica demonstrou, já na segunda metade do século XX, que a raça não existe e, consequentemente, que são absurdas as crenças baseadas na superioridade e inferioridade raciais dos grupos humanos. Porém, as crenças racistas não recuam, apesar de as pessoas terem mais acesso à ciência através da educação, o que mostra que a racionalidade em si não é suficiente para que todas as pessoas possam abrir mão de suas crenças racistas. Em outros termos, os racistas são movidos por outra racionalidade, que não é necessariamente científica

Embora seja uma realidade social que se evidencia por meio de práticas e parâmetros discriminatórios que produzem desigualdades patentes entre grupos raciais, sustentando um sistema de dominação e estrutura de poder que favorece a hegemonia da branquitude $^{4}$ na economia, no direito, na política e na cultura, o racismo

$4 \quad$ Branquitude é uma construção social que engendra significados que só em parte se manifesta na brancura dos corpos daqueles que são identificados como brancos. Nesse sentido, não se trata unicamente de uma identidade racial oposta à negritude, mas de um lugar de poder e hegemonia. De acordo com Maria Aparecida Bento (2002, p. 7), a branquitude é entendida "como um lugar de privilégio racial, 
é ainda entendido por muitos indivíduos e grupos sociais brasileiros como um conjunto de comportamentos preconceituosos e atos de discriminação pontuais. Não raro, há uma profunda resistência por parte da sociedade brasileira em admitir que as desigualdades sociais não se reproduzem apenas por uma questão socioeconômica de classe, mas são estruturadas também a partir das categorias de raça e gênero.

Como salienta Munanga (2017, p. 34), "para muitos, ainda, o Brasil não é um país preconceituoso e racista, sendo a discriminação sofrida por negros e não brancos, em geral, apenas uma questão econômica ou de classe social, sem ligação com os mitos de superioridade e inferioridade raciais". Nesse sentido, negros e não-brancos sofreriam discriminação não por conta da sua cor de pele e dos significados negativos atribuídos culturalmente a ela, mas sim, por serem pobres. Em outras palavras, "negros e brancos pobres, negros e brancos da classe média ou negros e brancos ricos não se discriminam entre si, tendo em vista que pertencem a classes econômicas iguais" (MUNANGA, 2017, p. 34). Ora, não é preciso muito para dar-se conta de que essa afirmação não é verdadeira para o contexto brasileiro. Vários são os casos noticiados cotidianamente em veículos de imprensa que relatam situações de violência ou constrangimento vividos por pessoas negras em espaços públicos e privados e isso, muitas vezes, a despeito de sua condição econômica. Aliás, neste país, o mecanismo de operação do racismo é tão efetivo que, mesmo após 132 anos de abolição da escravatura, a população negra permanece vivendo, em sua maioria, em condições de altíssima vulnerabilidade social. Segundo dados do IBGE ${ }^{5}$ divulgados em 2019, $75,2 \%$ dos brasileiros que apresentam rendimento diário abaixo de US $\$ 1,90$, isto é, abaixo da linha da pobreza, são pretos e pardos. $\mathrm{O}$

econômico e político, no qual a racialidade, não nomeada como tal, carregada de valores, de experiências, de identificações afetivas, acaba por definir a sociedade", ou seja, a branquitude é o elemento essencial para a preservação de hierarquias raciais.

5 Dados referentes à pesquisa IBGE sobre Desigualdades sociais por cor ou raça no Brasil, divulgada em novembro de 2019. 
rendimento médio domiciliar per capita da população branca foi de $\mathrm{R} \$ 1846,00$, em 2018 , e de $\mathrm{R} \$ 934,00$ para a população negra, o que significa que brancos possuem praticamente o dobro do rendimento médio de pretos e pardos. Em relação a domicílios sem acesso a serviços de saneamento, os dados da mesma pesquisa apontam que $12,5 \%$ da população preta ou parda reside em habitações sem coleta de lixo contra $6,0 \%$ da população branca, $17,9 \%$ da população preta ou parda vive em domicílios sem abastecimento de água ou rede geral contra $11,5 \%$ da população branca e $42,8 \%$ de pessoas pretas e pardas não possuem esgotamento sanitário por rede coletora ou pluvial em seus domicílios contra $26,5 \%$ de pessoas brancas.

Sobre a negação do racismo como vetor que produz desigualdades sociais, Abdias Nascimento (2016, pp. 100-101) diz que:

Já os mal-intencionados ou ingênuos estarão dizendo: - "Ora, os negros vivem nas favelas porque querem, porque escolheram assim; ou então porque não têm dinheiro, mas nunca por questões de raça”. E aqui nós entramos no labirinto raça-classe-sociedade. [...] Alegações de que esta estratificação é "não racial" ou "puramente social e econômica" são chavões que se repetem e racionalizações basicamente racistas: pois o fator racial determina a posição social e econômica na sociedade brasileira.

Se por um lado o apagamento da categoria raça nas explicações acerca da estratificação social e das desigualdades e a negação do racismo enquanto categoria estruturante da sociedade se fazem presentes no discurso corrente, por outro lado, a afirmação da existência do racismo no Brasil costuma se dar de maneira peculiar: reconhece-se a realidade de práticas sociais discriminatórias e comportamentos preconceituosos relacionados à raça, no entanto, os sujeitos não conseguem se reconhecer enquanto agentes que praticam tais ações e cooperam para a manutenção de uma ordem social racista. Nesse sentido, é como se o racismo operasse sem motor. Para exemplificar esse fenômeno, Munanga (2017) destaca os resultados de uma pesquisa científico-jornalística feita pelo jornal Folha de São Paulo e pelo Instituto Datafolha em 1995. Na referida 
pesquisa, " $89 \%$ dos brasileiros entrevistados aceitaram a existência do racismo no país, embora apenas 10\% deles tivessem confessado conhecer pessoas que discriminam, ou terem eles próprios discriminado" (MUNANGA, 2017, p. 35). Assim, o autor aponta que no Brasil, mesmo diante de uma flagrante situação de discriminação, os sujeitos tendem a justificá-la como um mal-entendido, de modo que "o brasileiro sempre encontra um jeito para escapar, às vezes depositando a culpa na própria pessoa segregada, considerando-a complexada" (MUNANGA, 2017, p. 37).

Essa especificidade do racismo no Brasil, de acordo com Kabengele Munanga está relacionada a fatores históricos que, no processo de subjetivação dos brasileiros e por meio da afirmação de um mito de harmonia das raças, faz com que as pessoas aqui acreditem que a ausência de leis e práticas explicitamente segregacionistas e a mestiçagem da população sejam provas cabais de que os sujeitos e a sociedade brasileira não são racistas. Dessa forma,

A dificuldade está justamente nas peculiaridades do racismo à brasileira, que o diferenciam de outras formas de manifestações discriminatórias na história da humanidade, como o regime nazista, as leis de Jim Crow no sul dos Estados Unidos e o apartheid na África do Sul, apenas para citar as mais conhecidas. Nesses modelos, o racismo foi explícito, institucionalizado e oficializado pelas leis daqueles países. Na Alemanha nazista e no regime do apartheid, praticou-se um racismo do Estado. No Brasil, ao contrário, o racismo é implícito, de fato, e nunca institucionalizado ou oficializado com base em princípios racialistas de pureza de sangue, de superioridade ou de inferioridade raciais. Por causa da ausência de leis segregacionistas, os brasileiros não se consideram racistas quando se comparam aos norte-americanos, sul-africanos e aos alemães nazistas. Em outros termos, os brasileiros se olham nos espelhos desses países e se percebem sem nenhuma mácula, em vez de fitarem o próprio espelho. Assim, ecoa dentro de muitos compatriotas uma voz muito forte que grita: "Não somos racistas, os racistas são os outros!" Essa voz forte e poderosa é o que chamo de inércia do mito de democracia racial brasileira. Como todos os mitos, funciona como uma crença, uma verdadeira realidade, uma ordem. Daí a dificuldade para arrancar do brasileiro uma confissão de que também seja racista (MUNANGA, 2017, pp. 37-38). 
A positivação da mestiçagem como marca identitária do povo brasileiro é um elemento importante na constituição e permanência do mito da democracia racial, bem como a forte convicção de que a formação dessa população mestiça se deu por intermédio de um encontro harmonioso entre brancos europeus, negros escravizados e indígenas nativos. Para a evidência histórica da violência cometida pelos brancos europeus no processo colonial, contrapõe-se a mestiçagem como fato, que, no imaginário dos sujeitos e narrativa nacional, apontaria para o enlaçamento afetivo e harmonia entre os grupos raciais. Nesse sentido, "o mito manipula alguns fatos evidenciados na realidade da sociedade brasileira, como a mestiçagem, as personalidades míticas e os símbolos da resistência cultural negra no país" com o intuito de "afirmar que somos um povo mestiço - ou seja, nem branco, nem negro e nem índio -, uma nova 'raça' brasileira, uma raça mestiça. Quem vai discriminar quem, se somos todos mestiços?” (MUNANGA, 2017, p. 38).

\section{Descolonização do currículo e educação antirracista: um reposicionamento da relação opressor-oprimido}

Após o recuo analítico proposto neste artigo, o qual consistiu na breve conceituação das ideias de raça, preconceito, discriminação e racismo, é chegado o momento de apresentar algumas considerações, a partir da obra freiriana, que auxiliam na proposição de uma educação antirracista.

Como salienta Nilma Lino Gomes (2017), o Movimento Negro, em seu histórico de resistência e enquanto agente social e político, pautou agendas importantes para a educação brasileira e, consequentemente, produziu conhecimento ao ressignificar e politizar conceitos sobre a realidade social e sobre si mesmo. Nas palavras da autora, "o Movimento Negro ressignifica e politiza a raça, compreendendo-a como construção social. Ele reeduca e emancipa a sociedade, a si próprio e ao Estado, produzindo novos conhecimentos e entendimentos sobre as relações étnico-raciais e o racismo no Brasil, 
em conexão com a diáspora africana" (GOMES, 2017, p. 38). Ora, esse apontamento inicial acerca dos movimentos organizados de resistência e luta da população negra é crucial, pois situa uma das grandes conquistas obtidas pelo Movimento Negro brasileiro, a saber, a aprovação da lei 10.639/03, que instituiu a obrigatoriedade do ensino de história e cultura africana e afro-brasileira nas escolas. Esse marco para a educação brasileira assinala para uma discussão que não nasce no século XXI com a aprovação da lei, mas que atravessa o debate sobre educação, relações étnico-raciais e combate às diferentes expressões do racismo. Aquilo que chamamos de descolonização do currículo já aparece nos escritos de Paulo Freire dos anos 70 e, como parte da argumentação do autor acerca da educação enquanto prática da liberdade e como processo de humanização que visa promover a conscientização dos sujeitos, toma a forma da defesa da necessidade de superação da consciência colonizada (1987, p. 28) - que em Freire será nomeada de consciência dominante ou consciência do opressor - já em Pedagogia do Oprimido, obra essa em que o pensador brasileiro faz referência direta a pensadores da crítica pós-colonial, como Albert Memmi, Amílcar Cabral e Franz Fanon.

Embora Paulo Freire, ao se referir ao neocolonialismo, não mobilize com profundidade a categoria raça, sabe-se, como já abordado neste artigo, que os processos neocoloniais têm a raça como elemento político fundamental, ainda que tenham sido motivados pela primeira crise do capitalismo. Assim, concebendo a questão da dominação e da contradição opressor-oprimido sob o viés da educação, Freire argumenta que a desumanização, para além de viabilidade ontológica, é uma realidade histórica que, junto da humanização, consiste em possibilidade dos sujeitos como seres inconclusos. De acordo com Freire (1978, p. 16), constatar a preocupação da educação como processo de humanização,

[...] implica, indiscutivelmente, reconhecer a desumanização, não apenas como viabilidade ontológica, mas como realidade histórica. É também, e talvez sobretudo, a partir dessa dolorosa constatação que os homens se perguntam sobre a outra viabilidade - a de sua desumanização. Ambas na raiz de sua inconclusão os inscrevem num permanente movimento de busca. 
Tomaz Tadeu da Silva, em sua análise de Pedagogia do Oprimido, afirma que a obra "está baseada numa dialética hegeliana das relações entre senhor e servo, ampliada e modificada pela leitura do primeiro Marx, do marxismo humanista de Erich Fromm, da fenomenologia existencialista e cristã e de críticos do processo de dominação colonial", sendo que, ainda de acordo com o autor, "o foco está, aqui, muito menos na dominação como um reflexo das relações econômicas e muito mais na dinâmica própria do processo de dominação" (SILVA, 2005, p. 208). Silva destaca também que a teorização de Freire é notoriamente pedagógica, "na medida em que ele não se limita a analisar como são a educação e a pedagogia existentes, mas apresenta uma teoria bastante elaborada de como elas devem ser" (SILVA, 2005, p. 208).

É sob a perspectiva analítica do processo de dominação, debatido no contexto da teoria educacional e da pedagogia, que em Cartas à Guiné-Bissau o pensador brasileiro irá refletir sobre a dialética opressor-oprimido na forma da relação colonizador-colonizado. Em uma das passagens introdutórias do livro, Paulo Freire argumenta que:

[...] a ideologia colonialista, procurava incutir nas crianças e nos jovens o perfil que deles fazia aquela ideologia. O de seres inferiores, incapazes, cuja única salvação estaria em tornar-se "brancos" ou "pretos de alma branca". Daí o descaso que essa escola necessariamente teria de ter por tudo o que dissesse de perto aos nacionais, chamados de "nativos". Mais do que descaso, a negação de tudo o que fosse representação mais autêntica da forma de ser dos nacionais: sua história, sua cultura, sua língua. A história dos colonizados "começava" com a chegada dos colonizadores, com sua presença "civilizatória"; a cultura dos colonizados, expressão de sua forma bárbara de compreender o mundo. Cultura, só a dos colonizadores. A música dos colonizados, seu ritmo, sua dança, seus bailes, a ligeireza de movimentos de seu corpo, sua criatividade em geral, nada disto tinha valor. [...] Por tudo isto é que, para os colonizados que passaram pela alienante experiência da educação colonial, a "positividade" desta educação ou de alguns de seus aspectos só existe quando, independentizando-se, a rejeitam e a superam. Quando, assumindo com seu povo, a sua história, se inserem no processo de "descolonização das mentes", a que faz referência Aristides Pereira; processo que se alonga no que Amílcar Cabral chamava de "re-africanização das mentalidades" (FREIRE, 1978, pp. 15-16). 
Observa-se no excerto supracitado que a consciência do opressor, ali entendida como do colonizador, se hospeda na consciência do oprimido, o colonizado, através da educação colonial que, por constituir elemento fulcral do processo de dominação, não emancipa o sujeito, isto é, não possibilita que ele, por meio da práxis, se liberte e encontre a sua palavra. Em vista disso, Freire evoca a noção de descolonização das mentes, postulada por Aristides Pereira, e de re-africanização das mentalidades, cunhada por Amílcar Cabral, para defender uma organização do conteúdo programático que supere o caráter elitista da educação e o método de conhecer nela implementado (FREIRE, 1978, p. 113). Como uma teorização pedagógica por excelência, Paulo Freire (1978, p. 113) enfatiza que a organização curricular "é um ato eminentemente político, como política é a atitude que assumimos na escolha das próprias técnicas e dos métodos para concretizar aquela tarefa [e] o caráter político de tal quefazer independe da consciência que tenhamos dele ou não". Nesse sentido, o autor conclui que "o saber como delimitar o que conhecer não pode estar separado do para que conhecer como das demais implicações deste ato", visto que "não há metodologistas neutros para ensinar como ensinar neutramente história ou geografia, língua nacional ou matemática" (FREIRE, 1978, p. 113).

Essa compreensão freiriana da necessidade de transformação radical do currículo e do método de conhecer característicos dos grupos dominantes aponta para o pioneirismo do autor em relação a um debate que se desenvolverá com mais força nas décadas seguintes. Segundo Silva (2005, p. 212), "se Paulo Freire se antecipou [...] à definição cultural de currículo que iria caracterizar depois a influência dos Estudos Culturais sobre os estudos curriculares, pode-se dizer também que ele inicia o que poderia chamar, no presente contexto, uma pedagogia pós-colonialista”. Entende-se aqui que essa perspectiva pós-colonialista sobre o currículo dialoga intimamente com a noção de descolonização do currículo defendida por militantes do Movimento Negro, educadores, pensadores do multiculturalismo e das relações étnico-raciais. A problematização 
acerca do silenciamento e invisibilidade de determinadas culturas, sobretudo daquelas que correspondem a epistemologias e relações com o saber ${ }^{6}$ que não se enquadram da moldura do conhecimento hegemônico, se faz necessária, principalmente no contexto de uma educação que se pretende antirracista, porque,

Quando se analisam de maneira atenta os conteúdos que são desenvolvidos de forma explícita na maioria das instituições escolares e aquilo que é enfatizado nas propostas curriculares, chama fortemente a atenção a arrasadora presença das culturas que podemos chamar de hegemônicas. As culturas ou vozes dos grupos sociais minoritários e/ou marginalizados que não dispõem de estruturas importantes de poder continuam ser silenciadas, quando não estereotipadas e deformadas, para anular suas possibilidades de reação (SANTOMÉ apud GOMES, 2012, p. 104).

Uma vez que as minorias sociais e os grupos raciais que não dispõem de estruturas importantes de poder têm as suas vozes silenciadas no currículo, tendo, por vezes, a representação de suas culturas estereotipada, o seu reconhecimento enquanto sujeito ocorre sem que ele se pense como parte de um grupo potente, que tem uma história, hábitos e saberes relevantes. No contexto de uma educação que contribui para o processo de dominação por meio da inculcação da consciência do opressor - a qual se revela na unilateralidade de uma proposta curricular pretensamente universal, mas que atualiza o conhecimento, saberes e valores da branquitude -, os grupos oprimidos são alijados da sua palavra, isto é, da sua voz na composição do diálogo. É sob esse prisma que Gomes (2012, p. 105) destaca a significância da lei 10.639/03 como ação em direção à descolonização do currículo, dado que ela "abre caminhos para a construção de uma educação antirracista que acarreta uma ruptura

6 De acordo com Charlot (2000, p. 80), “a relação com o saber é a relação com o mundo, com o outro e com ele mesmo, de um sujeito confrontado com a necessidade de aprender. [...] é o conjunto (organizado) das relações que um sujeito mantém com tudo quanto estiver relacionado com 'o aprender' e o saber”. Cf. CHARLOT, Bernard. Da relação com o saber: elementos para uma teoria. Porto Alegre: Artmed, 2000. 
epistemológica e curricular, na medida em que torna público e legítimo o 'falar' sobre a questão afro-brasileira e africana". Essa fala se pauta em um diálogo intercultural que se propõe a "ser emancipatório no interior da escola, ou seja, que pressupõe e considera a existência de um 'outro', conquanto sujeito ativo e concreto, com quem se fala e de quem se fala. E nesse sentido, incorpora conflitos, tensões e divergências".

Ora, é essa importância da conquista da palavra, da voz e da fala que a pensadora estadunidense e ativista do feminismo negro bell hooks capta na obra freiriana com precisão. Em sua narrativa sobre o encontro com o pensamento do educador brasileiro, ela revela que:

Quando encontrei a obra de Paulo Freire, bem num momento da minha vida em que estava começando a questionar profundamente a política da dominação, o impacto do racismo, do sexismo, da exploração de classe e da colonização que ocorre dentro dos próprios Estados Unidos, me senti fortemente identificada com os camponeses marginalizados de que ele fala e com meus irmãos e irmãs negros, meus camaradas da Guiné-Bissau. Veja você, eu chegava à universidade com a experiência de uma negra da zona rural do Sul dos Estados Unidos. Tinha vivido a luta pela dessegregação racial e estava na resistência sem ter uma linguagem política para formular esse processo. Paulo foi um dos pensadores cuja obra me deu uma linguagem. Ele me fez pensar profundamente sobre a construção de uma identidade na resistência. Uma frase isolada de Freire se tornou um mantra revolucionário para mim: "Não podemos entrar na luta como objetos para nos tornarmos sujeitos mais tarde". Realmente é difícil encontrar palavras adequadas para explicar como essa afirmação era uma porta fechada - essa luta me engajou num processo transformador de pensamento crítico. Essa experiência posicionou Freire, na minha mente e no meu coração, como um professor desafiador cuja obra alimentou minha própria luta contra o processo de colonização - a mentalidade colonizadora (hooks, 2017, pp. 66-67).

A linguagem que hooks afirma ter apreendido na obra de Freire pode ser entendida como um conjunto de categorias de pensamento e vocabulário que permitiram à autora refletir sobre os processos de dominação e sobre a sua condição de opressão, tornando possível, ao mesmo tempo, a identificação dela com os 
"esfarrapados do mundo" e os "condenados da terra" e o encontro de sua própria voz. Achar a própria voz é, para bell hooks (2017, p. 199), algo que sobrepuja "o ato de contar as próprias experiências. É usar estrategicamente esse ato de contar - achar a própria voz para também poder falar livremente sobre outros assuntos", ou seja, é libertar-se.

Por intermédio de uma pedagogia engajada que, na concepção da autora, consiste em uma pedagogia crítica, feminista e anticolonialista, a educação enquanto prática da liberdade tem como aspectos elementares o entusiasmo e a abordagem holística. Na perspectiva de hooks, a compreensão da união entre corpo, mente e espírito - que, portanto, estabelece uma ruptura com a concepção cartesiana de homem, a qual inaugura a racionalidade moderna eurocêntrica e branca - implica a necessidade de autoatualização docente. É esse processo de autoatualização que promove o bem-estar do professor, pois, de acordo com ela, não é possível educar sem que se esteja bem consigo mesmo. Com efeito, ousa-se inferir que não é possível orientar o processo de conscientização de alguém e criar condições para que ele encontre a sua própria voz, entendendo-se como sujeito histórico na luta contra as diferentes formas de dominação, sem que se tenha compreendido o próprio processo de emancipação e se esteja em harmonia consigo mesmo. Essa suposta harmonia e bem-estar não afastam as contradições. De acordo com a autora,

Pelo fato de as forças colonizadoras serem tão poderosas neste patriarcado capitalista de supremacia branca, parece que os negros sempre têm de renovar um compromisso com um processo político descolonizador que deve ser fundamental para a nossa vida, mas não é. E assim a obra de Freire, em seu entendimento global das lutas de libertação, sempre enfatiza que este é o importante estágio inicial da transformação - aquele momento histórico em que começamos a pensar criticamente sobre nós mesmas e nossa identidade diante das nossas circunstâncias políticas (hooks, 2017, p. 67).

Numa educação emancipadora e comprometida com o antirracismo, a libertação da consciência colonizada ocorre, seja para Freire ou para hooks, por meio do pensamento crítico e da recon- 
quista da palavra como voz, vez e lugar de enunciação onde o sujeito se entende como um ser constituído no curso do processo histórico, mas ainda inconcluso e, portanto, ativo. Assim, "para curar a cisão entre mente e corpo, nós, povos marginalizados e oprimidos, tentamos resgatar a nós mesmos e às nossas experiências através da língua" (hooks, 2017, p. 233). Para isso, a seleção de conteúdos programáticos que representem a diversidade étnico-cultural e permitam o acesso de estudantes negros e não-negros a saberes, conceitos, pensadores e conhecimentos subalternizados pela estrutura de poder da branquitude é fundamental. Só é possível encontrar a própria palavra, a voz violentamente silenciada pela dominação, na interlocução com o outro e no diálogo intercultural informado por um currículo plural, no qual as vozes dos antepassados, dos griots de ontem e de hoje podem ecoar. Como enfatiza Paulo Freire,

[...] o processo de libertação de um povo não se dá, em termos profundos e autênticos, se esse povo não reconquista a sua palavra, o direito de dizê-la, de "pronunciar" e de "nomear" o mundo. Dizer a palavra enquanto ter vOZ na transformação e recriação de sua sociedade: dizer a palavra enquanto libertar consigo sua língua da supremacia da língua dominante do colonizador. A imposição da língua do colonizador ao colonizado é uma condição fundamental para a dominação colonial, que se estende na dominação não colonial. [...] Só os colonizadores "têm" história, pois que a dos colonizados "começa" com a chegada ou com a presença "civilizatória” daqueles. Só os colonizadores "têm” cultura, arte, língua e são civilizados cidadãos nacionais do mundo "salvador". Aos colonizados lhes falta história, antes do esforço "benemérito" dos colonizadores. São incultos e bárbaros "nativos". Sem o direito de autodefinição, são "perfilados" pelos colonizadores. Não podem, por isso mesmo, "nomear-se" nem "nomear" ao mundo que lhes é roubado (FREIRE, 1978, p. 135).

\section{Considerações finais}

Os breves apontamentos destacados na argumentação deste texto indicam não só a relevância como também a atualidade do pensamento freiriano. Descolonizar o currículo, de acordo com o que foi debatido no presente artigo, é apenas parte da reestruturação de uma educação que se pretende emancipadora dos sujeitos e 
que toma forma em uma pedagogia do diálogo. Obviamente, desvencilhar-se dos meandros da opressão e da dominação colonial, patriarcal e capitalista implica tensionar as estruturas de poder e de saber operadas pelo racismo. Isso gera conflitos e demanda a descolonização do próprio pensamento e de suas categorias canônicas mobilizadas nas epistemologias hegemônicas.

\section{Referências}

ALMEIDA, Silvio. O que é racismo estrutural? Belo Horizonte: Letramento, 2018.

BENTO, Maria Aparecida Silva. Pactos narcísicos no racismo: branquitude e poder nas organizações empresariais e no poder público. Tese (Doutorado em Psicologia Escolar e do Desenvolvimento Humano) - Instituto de Psicologia, Universidade de São Paulo, São Paulo, 2002. Disponível em: https://teses.usp.br/ teses/disponiveis/47/47131/tde-18062019-181514/pt-br.php

CABRAL, Arlinda. Pedagogia do Oprimido. Revista Lusófona de Educação, Lisboa, n. 5, pp. 200-204, 2005. Disponível em: http://www.scielo.mec.pt/scielo. php?script $=$ sci_arttext\&pid $=$ S1645-72502005000100014

CAVALLEIRO, Eliane dos Santos. Do silêncio do lar ao silêncio escolar: racismo, preconceito e discriminação na educação infantil. São Paulo: Contexto, 2010.

CHARLOT, Bernard. Da relação com o saber: elementos para uma teoria. Porto Alegre: Artmed, 2000.

FREIRE, Paulo. Cartas à Guiné-Bissau: registros de uma experiência em processo. $2^{a}$ ed. Rio de Janeiro: Paz e Terra, 1978.

. Pedagogia do Oprimido. $17^{\mathrm{a}}$ ed. Rio de Janeiro: Paz e Terra, 1987.

GADOTTI, Moacir. Por que continuar lendo Pedagogia do oprimido? Revista de políticas públicas, São Luís, v. 16, pp. 459-461, 2012. Disponível em: https:// www. redalyc.org/pdf/3211/321129114017.pdf

GESTEIRA, L. A. M. G. A Guerra Fria e as Ditaduras Militares na América do Sul. Scientia Plena, vol. 10, n. 12, 2014. Disponível em: https://www.scientiaplena.org.br/sp/article/view/2062/1097\#

GOMES, Nilma Lino. O Movimento Negro educador: saberes construídos nas lutas por emancipação. Petrópolis: Vozes, 2017. 
. Relações étnico-raciais, educação e descolonização dos currículos, in: Currículo sem fronteiras, v. 12, n. 1, pp. 98-109, jan./abr., 2012. Disponível em: http:/ / www.curriculosemfronteiras.org/vol12iss1 articles/gomes.pdf

hooks, bell. Ensinando a transgredir: a educação como prática da liberdade. São Paulo: WMF Martins Fontes, 2017.

IBGE - INSTITUTO BRASILEIRO DE GEOGRAFIA E ESTATÍSTICA. Desigualdades sociais por cor ou raça no Brasil. Rio de Janeiro: 2019. Disponível em: https://www.ibge.gov.br/estatisticas/sociais/populacao/25844-desigualdades-sociais-por-cor-ou-raca.html? =\&t=publicacoes

MUNANGA, Kabengele. As ambiguidades do racismo à brasileira. In: KON, Noemi Moritz; SILVA, Maria Lúcia da Silva; ABUD, Cristiane Curi (orgs.). O racismo e o negro no Brasil: questões para a Psicanálise. São Paulo: Perspectiva, 2017, pp. 33-43.

Uma abordagem conceitual das noções de raça, racismo, identidade

e etnia. In: Programa de educação sobre o negro na sociedade brasileira. Niterói: EDUFF; 2004.

NASCIMENTO, Abdias. O genocídio do negro brasileiro: processo de racismo mascarado. São Paulo: Perspectiva, 2016.

SANTANA, Octacílio Antunes; SOUZA, Suzana Carvalho de. Pedagogia do Oprimido como referência: 50 anos de dados geohistóricos (1968-2017) e o perfil de seu leitor. Revista História da Educação (online), 2019, v. 23, pp. 1-31. Disponível em: https://www.scielo.br/pdf/heduc/v23/2236-3459-heduc-23-e83528.pdf

SANTOMÉ, Jurjo Torres. As culturas negadas e silenciadas no currículo. In: SILVA, Tomaz Tadeu da (Org.). Alienígenas na sala de aula. Petrópolis: Vozes, 1995. p. 159-189.

SCOCUGLIA, Afonso Celso. Origens e prospectiva do pensamento político-pedagógico de Paulo Freire. Educação e pesquisa, São Paulo, v. 25, n. 2, pp. 25-37, 1999. Disponível em: https://www.scielo.br/pdf/ep/v25n2/v25n2a03.pdf

SILVA, Tomaz Tadeu da. Pedagogia do oprimido versus Pedagogia dos conteúdos. In: Educação, Sociedade \& Culturas, Porto, n. 23, 2005, pp. 207-214. Disponível em: https://www.fpce.up.pt/ciie/revistaesc/ESC23/23-arquivo.pdf

VISENTINI, Paulo Gilberto Fagundes. Independência, marginalização e reafirmação da África (1957-2007). In: MACEDO, José Rivair. (org). Desvendando a história da África [online]. Porto Alegre: Editora da UFRGS, 2008. Diversidades series, pp. 123-137. 